\title{
Antibiofouling Polymer-Coated Superparamagnetic Iron Oxide Nanoparticles As Potential Magnetic Resonance Contrast Agents for In Vivo Cancer Imaging
}

Haerim Lee, Eunhae Lee, Dokyung Kim, Nam Kyu Jang, Yong Yeon Jeong*, and Sangyong Jon*

Synthesis of poly(TMSMA-r-PEGMA). Briefly, 5 mmol (1.25 g, 1 equiv) of TMSMA and 5 mmol (2.37 g, 1 equiv) of PEGMA were dissolved in $5 \mathrm{ml}$ of THF (anhydrous, $99.9 \%$, inhibitor-free). This mixture was degassed for 15 min using an $\mathrm{N}_{2}$ gas stream. After adding $0.1 \mathrm{mmol}$ of AIBN (10 mg, 0.01 equiv) as a radical initiator, the vial solution was sealed with a Teflon-lined screw cap. The polymerization reaction was carried out at $70{ }^{\circ} \mathrm{C}$ for $24 \mathrm{~h}$. The final product solution was stored at $4{ }^{\circ} \mathrm{C}$. The molecular weight of poly(TMSMA-r-PEGMA) was 66,769 with a polydispersity of 3.24 as measured by gel permeation chromatography using Waters 1515 isocratic pump and Waters 2414 Refractive Index detector. THF was used as eluent at a flow rate of 0.4 $\mathrm{mL} / \mathrm{min}$.

Characterizations of the SPION. FT-IR spectroscopy (SPECTRUM 2000 of PERKIN ELMER) was used to confirm the presence of the polymers in the SPION. The crystalline magnetite structures of IS- and SW-SPION were investigated by powder Xray diffractometry (XRD) using Ultma 3 of Rigaku. The X-ray diffraction patterns were

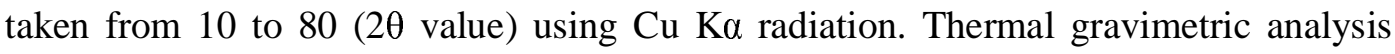
(TGA) was carried out using TGA 2050 Thermogravimetric Analyzer (TA instruments). 
The temperature of the sample gradually increased from $40{ }^{\circ} \mathrm{C}$ to $600{ }^{\circ} \mathrm{C}$ at a rate of $10{ }^{\circ} \mathrm{C} / \mathrm{min}$.
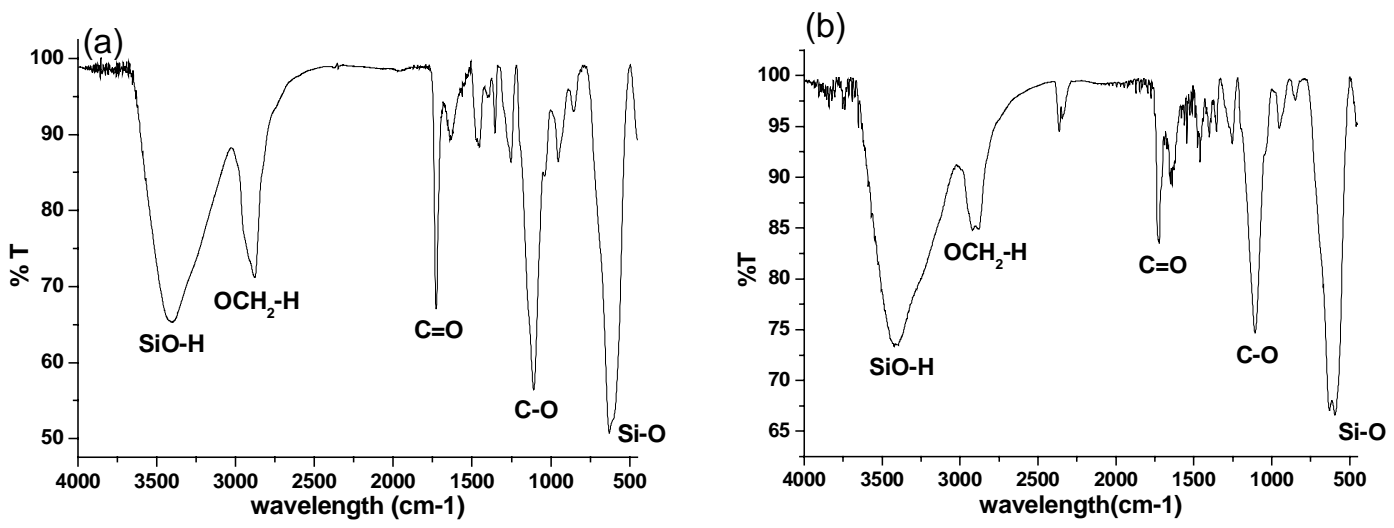

Figure S1. FT-IR spectra of (a) IS-SPION and (b) SW-SPION.

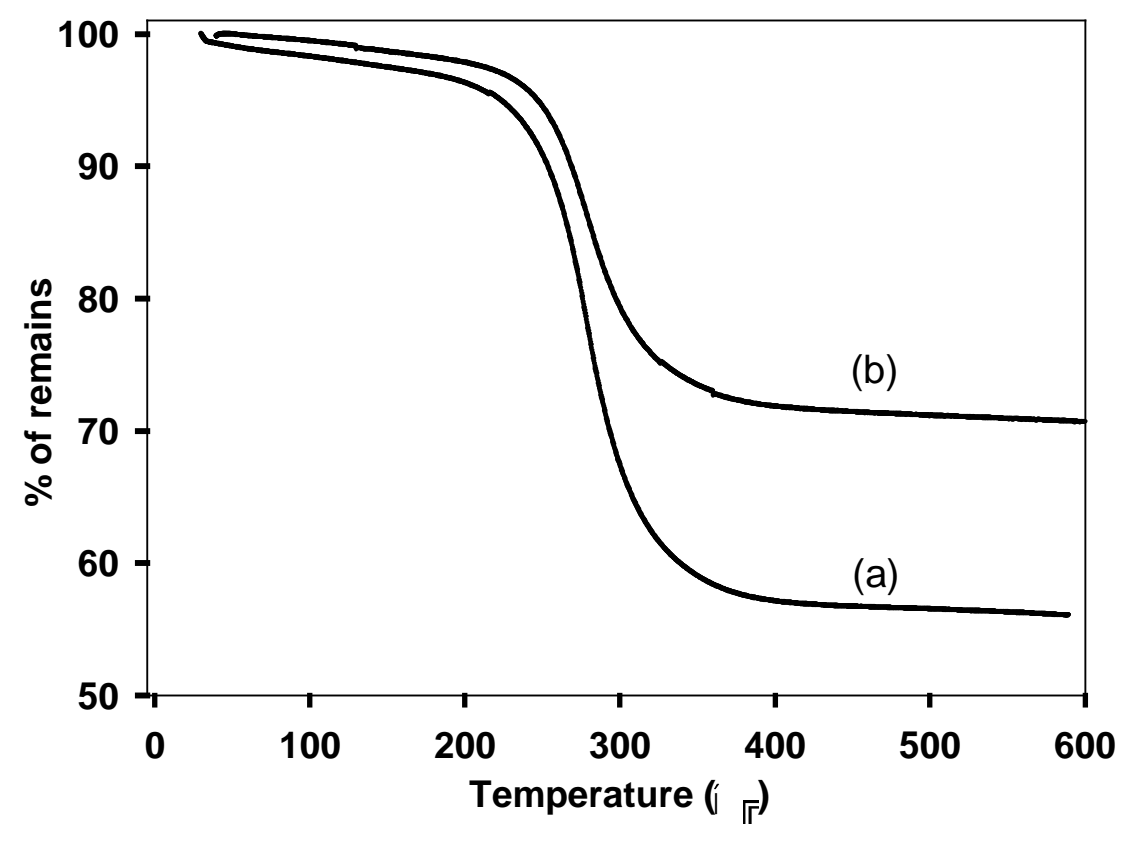

Figure S2. TGA graph of (a) IS-SPION and (b) SW-SPION. 

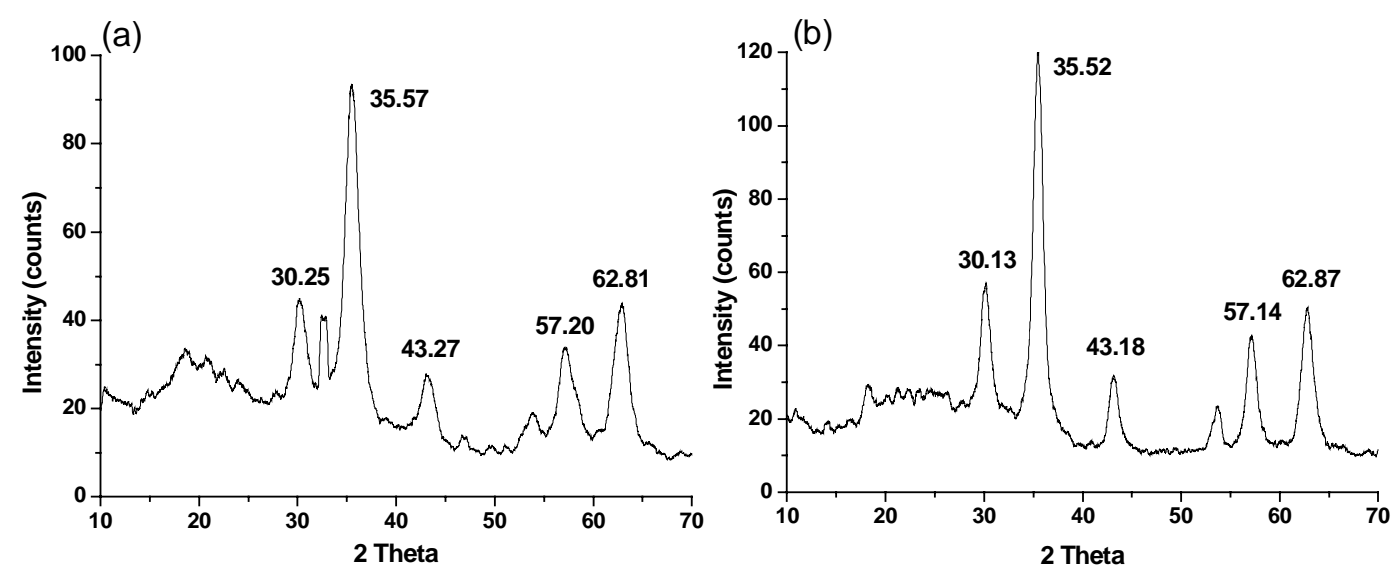

Figure S3. Powder X-ray diffraction (XRD) patterns of (a) IS-SPION and (b) SWSPION.

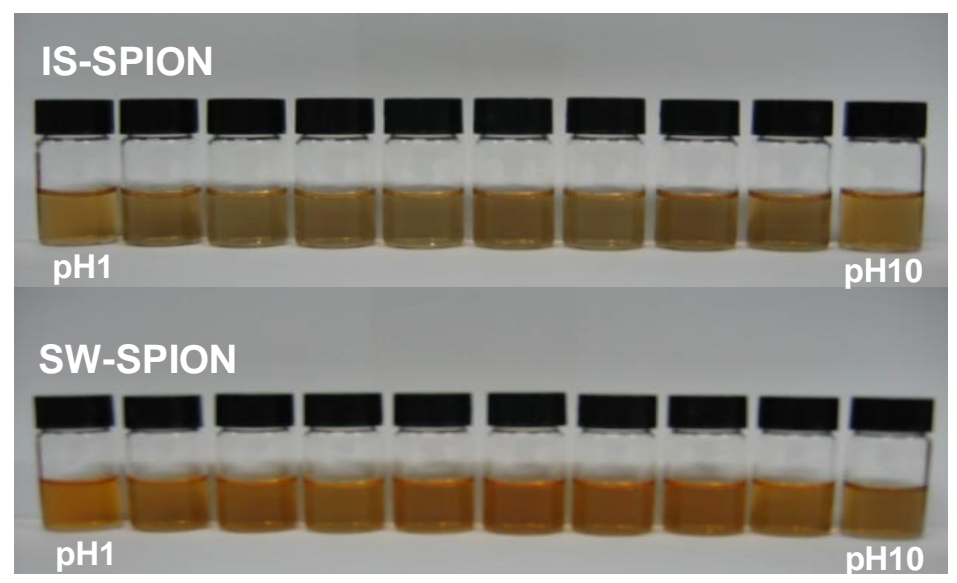

Figure S4. Photographs of IS-SPION and SW-SPION dispersed in distilled water at various $\mathrm{pHs}$. 